\title{
The Status and Development of Oral Choledochoscopy Diagnosis and Treatment of Biliary Tract Diseases
}

Jinyong $\mathrm{HaO}^{\mathrm{I}, 2}$

Xiaojun Huang ${ }^{1,2}$

'Department of Gastroenterology, Lanzhou University Second Hospital, Lanzhou, People's Republic of China; ${ }^{2}$ Gansu Provincial Digestive Endoscopy Engineering Research Center, Lanzhou, People's Republic of China
Correspondence: Jinyong Hao;

Xiaojun Huang

Department of Gastroenterology,

Lanzhou University Second Hospital,

No. 82 Linxia Road, Chengguan District,

Lanzhou City, Gansu Province, 730030,

People's Republic of China

Tel +86 I8I89556508

Email haojinyong517@163.com;

huangxj@|zu.edu.cn

\begin{abstract}
Choledochoscopy technology has realized the direct observation of bile duct lesions, and can be loaded with a variety of special accessories to perform the corresponding diagnosis and treatment operations, and has become an important means for the diagnosis of unexplained bile duct stricture and treatment of refractory bile duct stones. With the further enhancement of the imaging quality and operability, the clinical application of choledochoscopy has gradually expanded to the precise positioning of cholangiocarcinoma before surgical resection, the drainage of the gallbladder through the nipple, the removal of the displaced bile duct stent and other fields. This paper briefly reviewed the historical evolution of choledochoscopy and reviewed the latest clinical advances of oral choledochoscopy in the diagnosis and treatment of biliary tract diseases.
\end{abstract}

Keywords: oral choledochoscopy, SpyGlass, biliary stricture of unknown cause, refractory bile duct stones

\section{Introduction}

In 1923, Bakes designed a laryngoscope-like endoscope that, for the first time, enabled direct visual observation of the common bile duct, thereby making him a pioneer in the field of choledochoscopy. ${ }^{1}$ In the following few decades, intraoperative cholangioscopy is inserted through the wound in biliary tract surgery, and post-operative T-tube tract cholangioscopy is inserted through the T-canal sinus, were both developed and generally applied. ${ }^{2}$ In the late $1970 \mathrm{~s}$, based on endoscopic retrograde cholangiopancreatography (ERCP), endoscopic sphincterotomy (EST), and endoscopic papillary balloon dilation (EPBD), researchers developed two individual types of per-oral cholangioscopy (POCS) techniques. Kawai et al proposed a duodenoscope as the main mirror device with a microfiber endoscope as a biliary tract sub-mirror and main mirror of the sub-mirror. ${ }^{3}$ Urakami et al proposed ultrafine endoscopy of the upper digestive tract, supported with a direct per-oral choledochoscope with conducting wire, sacculus, and other devices. ${ }^{4}$ In the early 1980s, Nimura et al reported percutaneous transhepatic cholangioscopy (PTCS) followed by sinus dilatation and insertion of a choledochoscope through the sinus. ${ }^{5}$ In 2005, Boston Scientific Corporation of USA launched its POCS system, SpyGlass ${ }^{\mathrm{TM}}$, a catheter-based device that can be operated by a single individual. $^{6}$ In 2015, the developers released the second generation, the SpyGlass TM Digital System "DS", in which they replaced the fiber optic probe 
with a digital one, resulting in a four-times enhanced image resolution. ${ }^{7}$ Since then, the development of choledochoscopy technology has continued and currently includes the following features: 1) higher image quality, upgraded from optical imaging to high-definition electronic imaging, with selected models being equipped with image enhancement functions, such as narrow-band imaging (NBI) and the Fuji intelligent chromo endoscopy (FICE) technique; 2) better maneuverability, specifically, additional deflection directions, a larger accessory channel, and more complete special attachments ${ }^{8}$ (see Figure 1).

In recent years, minimally invasive POCS and PTCs have gradually replaced invasive intraoperative/postoperative choledochoscopy techniques. Percutaneous transhepatic cholangioscopy tends to be limited because it is time-consuming, can easily cause patient discomfort and may cause bile leakage and/or bleeding. As such, PTCS is typically recommended for specific patients with deviations in gastrointestinal anatomical structure and for removing intrahepatic bile-duct stones where other POCS are not feasible or ineffective. ${ }^{9}$ In this paper, the clinical application of POCS in the diagnosis and treatment of biliary tract diseases is broadly summarized.

\section{Platform for Per-Oral Choledochoscopy Technology}

Per-oral cholangioscopy can currently be divided into two types. The first is catheter-based per-oral indirect choledochoscopy and includes the biliary tract main and submirror type and SpyGlass. The second type is direct POCS, based on ultrafine endoscopy of the upper digestive tract. These POCS types can employ multiple special attachments via attachment channels, which can be employed in surgery, diagnosis, and the treatment of biliary tract diseases.

\section{Per-Oral Cholangioscopy Instrument: Main Body \\ Biliary Tract Main and Sub-Mirror}

Close collaboration between two endoscopists is required to control the biliary tract main mirror and sub-mirrors. One endoscopist is responsible for controlling the duodenoscope (the main mirror) to perform EST and/or EPBD. A second endoscopist controls the accessorial passage of the microfiber endoscope through the main mirror (the sub-mirror), which enters the target bile duct along a conducting wire, and uses it to perform subsequent diagnosis and treatment. ${ }^{10}$ The CHF-B260 (Olympus Corporation) is a new generation of biliary tract main and sub-mirror system, the latter of which has an outer diameter of $3.4 \mathrm{~mm}$. The distal end can achieve bidirectional deflection, and the endoscope is equipped with a single accessory channel with an inner diameter of $1.2 \mathrm{~mm}$. The microscope can produce highresolution electronic imaging and has NBI enhancement capabilities for the detailed examination of biliary mucosa. ${ }^{11}$ The advantages of the biliary tract main and submirrors system include easy access to the biliary tract with outstanding imaging quality; however, the endoscope requires two people to operate, which is laborious and timeconsuming, and the sub-mirror is fragile and can easily be damaged, which makes its operational cost high. ${ }^{12}$

\section{SpyGlass}

The first generation SpyGlass (SpyGlass Legacy) system comprises a disposable $3.3 \mathrm{~mm}$ transmission catheter and a reusable fiber optic probe with an outer diameter (OD) of $0.77 \mathrm{~mm}$. The distal end of the transmission tube can realize deflection in four directions. The tube body is mounted with a single fiber optic probe channel with an inner diameter of $0.9 \mathrm{~mm}$, and a single accessory channel with an inner diameter of $1.2 \mathrm{~mm}$, and a dual flush channel with an inner diameter of $0.6 \mathrm{~mm}$. More importantly, the delivery

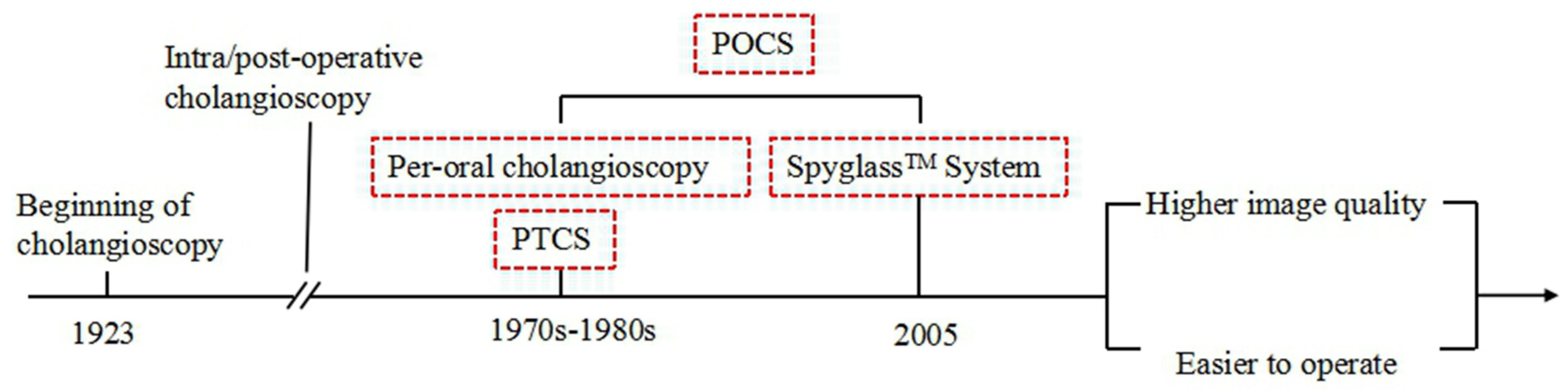

Figure I The historical evolution of choledochoscopy technology. 
catheter is also designed with an operating handle that can adjust the above functions and can be fixed to the duodenoscope. In this way, only one senior endoscopic physician can achieve effects similar to the biliary tract main and submirror device. Following the EST or EPBD, the maneuvering handle of the delivery catheter with the fiber optic probe is fixed to the duodenoscope; then, the main part of the catheter enters the target bile duct through the adnexal channel of the duodenoscope along a conducting wire. In this way, only one physician is needed to control the duodenoscope and SpyGlass system for follow-up diagnosis and treatment. ${ }^{13}$ SpyGlass $^{\mathrm{TM}}$ DS is an updated version of SpyGlass Legacy that offers high-resolution electronic imaging with a newly added negative pressure suction function. Additionally, the transfer tube tip is tapered for increased maneuverability. ${ }^{14}$ The advantages of the SpyGlass include easy access to the biliary tract, excellent imaging quality and single-person operation, but the use of disposable accessories significantly increases the operating cost. ${ }^{15}$

\section{Direct Per-Oral Choledochoscopy}

Direct POCS is applied as follows. Following EST or EPBD, the conducting wire and sacculus are inserted into the hepatic duct and anchored through the adnexal channel of the duodenoscope. The duodenoscope is then withdrawn and removed, and an ultrafine endoscope can be inserted into the upper digestive tract and enter the target bile duct along the guidewire for follow-up diagnosis and treatment. ${ }^{16}$ Reports have indicated that an outer sleeve, endoloop, and other auxiliary devices were used to conduct direct POCS. ${ }^{17}$ Beyna et al developed a new type of direct POCS insertion attachment with an outer diameter of $4.9 \mathrm{~mm}$, which supports mixed articulation $\left(90^{\circ}\right.$ above and below the proximal end; distal top, $200^{\circ}$, bottom, $100^{\circ}$ ), and where the endoscopic surface is equipped with dual accessory channels (inner diameter, 2.2/ $1.0 \mathrm{~mm}$ ). The attachment is also able to realize high-definition electronic imaging with NBI enhancement, which improves the success rate of bare-handed intubation. ${ }^{18}$ The advantages of using a direct POCS are outstanding image quality, food fieldof-view support, and a large attachment channel. However, it requires high technology; additionally, the outer diameter is relatively thick, making it difficult to reach the smaller bile duct $^{19}$ (see Table 1).

\section{Per-Oral Cholangioscopy Attachment Diagnostic Attachment}

An important basis for the diagnosis of biliary tract diseases is performing tissue biopsy guided by POCS under direct observation. The inner diameter of the accessory channel of the biliary tract main and sub-mirrors of SpyGlass is small $(1.2 \mathrm{~mm})$ and can only be used with the SpyBite $^{\mathrm{TM}}$

Table I Comparison of Different Types of POCS

\begin{tabular}{|c|c|c|c|}
\hline Technical & Direct Per-Oral Choledochoscopy & Per-Oral Indirect Chol & choscopy \\
\hline $\begin{array}{l}\text { Representative } \\
\text { products }\end{array}$ & Direct per-oral choledochoscopy & $\begin{array}{l}\text { Biliary tract main and } \\
\text { sub-mirror }\end{array}$ & SpyGlass ${ }^{\text {TM }}$ DS \\
\hline Operator & I person & 2 persons & I person \\
\hline Operating mode & $\begin{array}{l}\text { (1) Complex } \\
\text { (2) A sphincterotomy of the papilla is performed and } \\
\text { a duodenoscope is removed } \\
\text { (3) A special accessory is needed to fix the guidewire into the } \\
\text { biliary tract and insert the guidewire into the } \\
\text { choledochoscope }\end{array}$ & $\begin{array}{l}\text { (1) Complex } \\
\text { (2) The duodenoscopy } \\
\text { requires a two-person } \\
\text { operation }\end{array}$ & $\begin{array}{l}\text { (1) Relatively simple } \\
\text { (2) The duodenoscope is } \\
\text { operated by one person } \\
\text { only }\end{array}$ \\
\hline $\begin{array}{l}\text { The lens barrel } \\
\text { diameter }\end{array}$ & $\begin{array}{l}\text { (1) About } 5 \mathrm{~mm} \\
\text { (2) Cannot pass through the duodenoscopic forceps }\end{array}$ & $\begin{array}{l}\text { (1) } 3.4 \mathrm{~mm} \\
\text { (2) Can pass through the } \\
\text { duodenoscopic forceps }\end{array}$ & $\begin{array}{l}\text { (1) } 3.3 \mathrm{~mm} \\
\text { (2) Can pass through the } \\
\text { duodenoscopic forceps }\end{array}$ \\
\hline $\begin{array}{l}\text { Front-end } \\
\text { direction } \\
\text { adjustment }\end{array}$ & Two-quadrant & Two-quadrant & Four-quadrant \\
\hline Cost & High & High & Relatively high \\
\hline
\end{tabular}


microbiopsy forceps to perform a tissue biopsy. Thus, typically, multiple clamps are required to ensure adequate sampling quantity. The inner diameter of the accessory channel of the direct POCS is larger $(2.2 \mathrm{~mm})$, which allows for standard pediatric biopsy forceps to achieve a smooth through. ${ }^{20}$ Furthermore, in recent years, it has been reported that probebased confocal laser endomicroscopy (pCLE) can be applied using the SpyGlass ${ }^{\mathrm{TM}}$ DS attachment channel to realize realtime histological imaging of biliary mucosa and improve the sensitivity of diagnosing the causes of unknown bile duct stenosis. $^{21}$

\section{Therapeutic Attachment}

"Effective treatment" refers to treating refractory bile duct calculus using POCS electrohydraulic lithotripsy (EHL) under direct observable guidance and laser lithotripsy (LL). In the case of the former, this involves inserting the high-pressure probe of a hydroelectric lithotripsy meter into the accessory channel of the POCS. In this way, high-frequency hydraulic waves are generated by an underwater discharge to break the calculus. ${ }^{22}$ The second method is to insert the fiber optic probe of the laser lithotripter meter into the accessory channel of the POCS, where the resulting shock wave, generated by plasma expansion, will help to break up the calculus. ${ }^{23}$ Equipped with a dedicated double flush channel, SpyGlass is better suitable for realizing EHL. ${ }^{24}$ In addition, it was reported that radiofrequency ablation (RFA) electrodes could be inserted into the adnexal channel of the SpyGlass ${ }^{\mathrm{TM}}$ DS system to alleviate the treatment for nonresectable cholangiocarcinoma. ${ }^{25}$

\section{Clinical Application of Per-Oral Choledochoscope Technology}

Per-oral cholangioscopy can be used for clinical diagnostic or therapeutic purposes. Diagnostic POCS is most commonly used to identify a biliary stricture with an unknown cause using visual impressions and a directly observable guided biopsy. Therapeutic POCS is primarily used for the treatment of a refractory bile duct calculus by direct observation-guided EHL and LL.

\section{Per-Oral Cholangioscopy Used in the Diagnosis of Biliary Tract Diseases Determining the Nature of Stenosis of the Bile Duct with an Unknown Cause}

Stenosis of the bile duct has both benign and malignant types. Malignant bile duct stenosis refers to a stricture caused by compression of the bile duct from a bile duct carcinoma or other metastatic tumors. ${ }^{26}$ Cell-brushing examination under ERCP is considered the gold standard for the diagnosis of malignant bile duct stricture. However, its overall sensitivity was previously indicated as being only $41.6 \% .{ }^{27}$ Using computed tomography (CT), endoscopic ultrasonography (EUS), magnetic resonance imaging cholangiopancreatography (MRCP), and other imaging examinations, as well as ERCP cell-brushing under the brush, biliary stenosis of unknown origin referred to as bile duct stenosis in which no definite diagnosis can be made. ${ }^{28}$ Furthermore, POCS allows for direct observation of the lesion site and for performing tissue biopsy under direct guidance. It also has unique advantages for determining the unknown causes of bile duct stricture. Miyabe et al found that high-grade biliary intraepithelial neoplasia (BilIN-3) could be detected early by SpyGlass DS Cholangioscopy. They had a good experience with an 84-year-old male patient with epigastralgia. ${ }^{29}$

There is no uniform standard for the interpretation of visual impressions gained from POCS of malignant bile duct strictures. It is currently generally accepted that, microscopically, irregular tortuous dilatation of blood vessels, polypoid masses, and fish-egg-like lesions are closely related to malignant tumors. ${ }^{30}$ Based on these evaluation criteria, a multi-center prospective cohort study was conducted by Osanai et al, who found that POCS presented significantly higher sensitivity $(100 \%$ vs $57.9 \%, \mathrm{P}<0.05)$ and accuracy $(93.4 \%$ vs $78.1 \%, \mathrm{P}<0.05)$ for the diagnosis of bile duct stenosis with an unknown cause compared with ERCP. ${ }^{31}$ Korrapati et al conducted a meta-analysis of 10 cohort studies in which visual impressions under POCS were used to diagnose unexplained bile-duct stenosis. The sensitivity, specificity, and accuracy among these studies were $93 \%, 85 \%$, and $89 \%$, respectively. The POCS involved in this study included choledochal biliary tract main and sub-mirrors, SpyGlass Legacy, and direct POCS systems. Because it has an optical imaging function only, the diagnostic sensitivity of visual impressions using SpyGlass Legacy is much lower compared with the biliary tract main and sub-mirror approach. ${ }^{32}$ The secondgeneration SpyGlass ${ }^{\mathrm{TM}}$ DS addresses this problem through upgraded high-definition electronic imaging. Navaneethan et al performed a multi-center study involving 44 patients with unexplained bile duct stenosis; their results showed that the diagnostic sensitivity and specificity of visual impression under SpyGlass ${ }^{\mathrm{TM}}$ DS were $90 \%$ and $95.8 \%$, respectively. ${ }^{33}$ 
Under direct observational guidance, POCS can be biopsied from the site of bile duct stenosis for pathological analysis. Draganov et al performed a prospective paired study involving 26 patients with unexplained bile duct stenosis. All participants underwent cell-brushing examination under ERCP and tissue biopsy under direct observational guidance provided by SpyGlass Legacy. The latter manifested significantly higher diagnostic sensitivity $(76.5 \%$ vs $5.9 \%, \mathrm{P}<0.0001)$ and accuracy $(84.6 \%$ vs $53.8 \% ; \mathrm{P}=0.0215) .{ }^{34}$ According to a retrospective cohort study in 2018, the diagnostic efficiency (sensitivity, $62.5 \%$; specificity $90.0 \%$ ) of biopsy guided by SpyGlass DS for bile duct stricture with an unknown cause was lower compared with using visual impressions (sensitivity, $88.9 \%$; specificity, $97.6 \%$ ). ${ }^{35}$ These results suggest that although tissue biopsy guided by POCS under direct observation yields better results than cell-brushing examination under ERCP, it can currently only be used as supplementary support for visual impressions under POCS.

\section{Accurate Localization of Cholangiocarcinoma Prior to Surgical Resection}

Cholangiocarcinoma tends to be associated with extensive intraepithelial tumor spread (ITS) that is $20 \mathrm{~mm}$ or larger. Hence, accurate localization of cholangiocarcinoma and assessment of ITS range for identifying the incisive margin is necessary to achieve radical resection. ${ }^{36}$ According to the findings of Kawakami et al, the accuracy of ERCP, POCS visual impressions, and POCS visual impressions plus directly observable guided biopsy in diagnosing ITS was $22 \%, 77 \%$, and $100 \%$, respectively. ${ }^{37}$ Osanai et al performed a multi-center prospective cohort study involving 87 patients with extrahepatic bile duct carcinoma, and the results showed that the accuracy of ERCP, visual impressions under a biliary tract main and sub-mirror system, and visual impression under a biliary tract main and sub-mirror plus direct vision guided biopsy approach in diagnosing the range of ITS was $73.5 \%, 83.7 \%$, and $92.9 \%$, respectively. ${ }^{31}$ In a 2018 study involving 14 elderly patients with bile duct carcinoma (mean age 75 years), the accuracy of visual impression plus directly observable guided biopsy under SpyGlass ${ }^{\mathrm{TM}}$ DS in the diagnosis of ITS was $88 \%$, with no surgery-related complications. ${ }^{38}$

\section{Residual Detection of Bile Duct Calculus Following Routine Lithotomy}

Endoscopic retrograde cholangiopancreatography lithotomy (including net basket lithotomy, balloon lithotomy, and mechanical lithotripsy) is the primary method for the clinical treatment of bile duct stones. However, it was reported that patients receiving conventional ERCP lithotomy experienced a high level of residual stones. ${ }^{39}$ These remaining calculi are typically small in diameter $(2-5 \mathrm{~mm})$ and, as such, not detectable by imaging tests. It is difficult to distinguish small calculi with a density similar to liver parenchyma via CT scan. ${ }^{40}$ In some instances, EUS may miss small, high-density calculi during diagnosis due to the presence of silent shadows. ${ }^{41}$ The sensitivity of MRCP was relatively high, but its cost is higher compared with POCS. ${ }^{42}$ Huang et al conducted a prospective study involving 22 patients with extrahepatic bile duct stones. All patients underwent direct POCS following conventional ERCP lithotomy, which required an average of $8.2 \pm 2.9$ minutes to complete. Residual stones were detected in five patients. ${ }^{43}$ A similar study in 2019 also showed that direct POCS was able to detect residual stones following conventional ERCP removal (19 detected among 79 cases in total), and no surgery-related complications were detected. ${ }^{44}$

\section{Others}

In addition to the above diagnostic uses, POCS can also be used for staging cholangiocarcinoma ${ }^{45}$ evaluation of bile duct ischemia after liver transplantation. ${ }^{46}$

\section{Per-Oral Cholangioscopy Used in the Treatment of Biliary Tract Diseases Removal of Refractory Bile Duct Calculus}

Approximately $10-15 \%$ of bile duct stones cannot be successfully removed by conventional ERCP lithotomy due to their size ( $\geq 15 \mathrm{~mm}$ ), shape (eg, piston-like stones), location (embedded stones), and other factors; these are clinically referred to as refractory calculi. ${ }^{47}$ Under the direct guidance of POCS, EHL and LL can accurately target and break up refractory stones, thereby achieving a high complete stone clearance rate and avoiding the risk of bile duct injury.

Korrapati et al performed a meta-analysis of 31 cohort studies on the treatment of refractory bile duct calculus with EHL and LL under POCS directly observable guidance and found that the combined stone complete clearance rate was $88 \%$ and the adverse event rate was $7 \% .{ }^{32}$ Arya et al performed a multi-center retrospective study involving 93 patients with refractory bile duct stones following the failure of conventional ERCP lithotomy. All patients received EHL under the guidance of a biliary duct 
master mirror. The success rate of lithotripsy was $96 \%$, and the complete stone clearance rate was $90 \%$. Special attention should be given to the fact that $24 \%$ of patients required EHL more than twice to remove stones. ${ }^{48}$ Carlos Robles-Medranda et al analyzed the factors associated with complete or partial biliary stone clearance achieved with EHL delivered via POCS in 118 patients. Complete biliary stone clearance was achieved by EHL in $94.9 \%$ patients. A stone size $>20 \mathrm{~mm}$ (OR: 1.020, $\mathrm{P}<0.001)$ and the number of stones $\geq 3$ (OR: $1.276, \mathrm{P}<001$ ) was associated with partial biliary stone clearance. ${ }^{49}$ In 2017 , a large retrospective cohort study included 407 patients with refractory bile duct stones, 306 of whom received EHL under direct observational guidance with SpyGlass ${ }^{\mathrm{TM}}$ DS and 101 patients received LL under directly observed guidance with SpyGlass ${ }^{\mathrm{TM}}$ DS. The mean operating time for the EHL group (73.9 min) was longer compared with the LL group (49.9 $\mathrm{min}$ ), and the combined stone clearance rate was $97.3 \% .{ }^{50}$ According to a study conducted by Moon et al, 18 patients with refractory bile duct stones were treated with LL under direct oral choledochoscope guidance, and the complete stone clearance rate was $88.9 \%$, without any surgery-related complications. ${ }^{51}$

The advantage of EHL and LL under the direct guidance of POCS is that it can reduce the need for X-ray fluoroscopy imaging. Thus, it can be used for specific patients who are sensitive to radiation/contrasting agents. Barakat et al evaluated the feasibility of EHL under directly observed guidance with SpyGlass ${ }^{\mathrm{TM}}$ DS in a radiation-free environment for the treatment of noncomplex choledocholithiasis. All patients successfully achieved intubation and lithotripsy, independent of X-ray fluoroscopy; short-term imaging was required in only $5 \%$ of patients to determine whether calculi had been completely removed. ${ }^{52}$ Another advantage of EHL and LL under the guidance of directly observable POCS is that it can reduce the need for mechanical lithotripsy. ${ }^{53}$

\section{Radiofrequency Ablation of Cholangiocarcinoma}

Radiofrequency ablation may damage cells through the thermal effects of high-frequency alternating current and eventually lead to cell coagulation necrosis. Multiple studies have shown that RFA under ERCP may improve the unobstructed stent degree and survival in patients with cholangiocarcinoma ${ }^{54,55}$ Nonetheless, given that this procedure is typically performed only under the guidance of $\mathrm{X}$-ray fluoroscopy, it is easy to accidentally contact the normal bile duct wall during the ablation of tumor tissue, causing bleeding, perforation, infection, and other serious surgery-related complications. ${ }^{56}$ According to a retrospective cohort study in 2017, RFA under direct observational guidance using SpyGlass ${ }^{\mathrm{TM}}$ DS was successful in 12 patients with cholangiocarcinoma, with only one patient developing postoperative cholangitis. ${ }^{57}$ This indicated that RFA under the guidance of directly observable POCS is safe and feasible. However, its long-term clinical efficacy in non-resectable cholangiocarcinoma remains unclear.

\section{Auxiliary Placement of the Conducting Wire}

Balloon dilatation and stent implantation under ERCP are the main approaches for the clinical treatment of stenosis of the bile duct. The success rate, however, remains unsatisfactory. The reason for this is that the conducting wire cannot pass through the stenosis for some patients with a complex bile duct stricture; as a result, there is no way to guide the subsequent (follow-up) therapeutic procedures. ${ }^{58}$ In a retrospective study, Bokemeyer et al evaluated the feasibility of placing an auxiliary conducting wire through the bile duct stricture under direct guidance delivered by SpyGlass $^{\mathrm{TM}}$ DS. In this study, 23 patients who experienced failure of conducting wire placement under conventional ERCP received a total of 30 guide-wire placement attempts under direct observation guided by SpyGlass ${ }^{\mathrm{TM}}$ DS. The success rate was $70 \%$ and the adverse event rate was $6.7 \% .^{59}$ This result indicated that an auxiliary conducting wire passing through a bile duct stricture under POCS direct guidance was safe and feasible, and contributed to avoiding invasive procedures, such as PTCS.

\section{Others}

In addition to the approaches noted above, among others, POCS can be used for pre-nipple gallbladder drainage ${ }^{60}$ removal of a displaced biliary stent. ${ }^{61}$

\section{Security of Per-Oral Cholangioscopy}

Whether POCS will increase the incidence of adverse events remains debatable Studies have shown that POCS is relatively safe and that its overall adverse event rates were consistent with conventional ERCP. ${ }^{62}$ Nonetheless, this rate for POCS was significantly higher compared with conventional ERCP ( $7 \%$ vs $2.9 \%$, respectively), and postoperative cholangitis was most frequently observed for POCS compared with ERCP (1.0\% vs $0.2 \%) .{ }^{63}$ The expert consensus on POCS security is currently that, when using 
gas injection, $\mathrm{CO} 2$ rather than air must be used to avoid the formation of a fatal air embolism. ${ }^{64}$

\section{Conclusion}

At present, the technique of POCS has developed rapidly. The SpyGlass $^{\mathrm{TM}}$ DS produced by Boston Scientific Corporation of USA has higher pixel and resolution, and has the functions of water delivery and direct biopsy. It will be better for the accurate presurgical diagnosis and evaluation of patients with bile duct diseases, and is more conducive to clinicians to make the next diagnosis and treatment plan for patients.

\section{Future Prospects}

Briefly, the rapid development of POCS (particularly SpyGlass, which can be operated by a single individual) can help endoscopic physicians to "enter" the biliary tract system to perform diagnosis and treatment safely and efficiently, thereby significantly expanding the clinical indications of biliary endoscopy. Currently, POCS is primarily used to determine the nature of unexplained bile duct strictures and for the removal of refractory bile duct calculi. It is noted that the fiber optical waveguide used in SpyGlass can only bend within a limited range. Furthermore, when compressed, the resulting attenuation will affect the image. While conducting $* * * *$ the smallest mistake may negatively affect the resulting image. In addition, the sensitivity of tissue biopsy guided by POCS under direct observation remains unsatisfactory; this may to due to the limitations imposed by the small size of SpyBite biopsy forceps. Hence, POCS is limited to a small number of large medical institutions because of its highly technical requirements and expensive operating costs. The development and application of new materials, imaging technologies, and special attachments is expected to overcome these difficulties. In the meantime, POCS currently remains the preferred strategy for the diagnosis and treatment of biliary tract diseases.

\section{Abbreviations}

CT, computed tomography; EHL, electrohydraulic lithotripsy; EPBD, endoscopic papillary balloon dilation; ERCP, endoscopic retrograde cholangiopancreatography; EST, endoscopic sphincterotomy; EUS, endoscopic ultrasonography; FICE, Fuji intelligent chromo endoscopy; ITS, intraepithelial tumor spread; LL, laser lithotripsy; MRCP, magnetic resonance cholangiopancreatography; NBI, narrow-band imaging; pCLE, probe-based confocal laser endomicroscopy; POCS, per-oral choledochoscopy technology; PTCS, percutaneous transhepatic cholangioscopy; RFA, radiofrequency ablation.

\section{Funding}

Key research and development plan of Gansu province (20YF8FA076).

\section{Disclosure}

All authors reported no conflicts of interest for this work.

\section{References}

1. May RE, Corfield A. An assessment of operative choledochoscopy-a worthwhile procedure or not? Ann R Coll Surg Engl. 1985;67(2):9698.

2. Häberlin P. [Cholangioscopy]. Helv Chir Acta. 1966;33(1):78-80. [Portugese]

3. Kawai K, Nakajima M, Akasaka Y, Shimamotu K, Murakami K. Eine neue endoskopische Technik: die perorale CholedochoPankreatikoskopie [A new endoscopic method: the peroral choledocho-pancreatoscopy (author's transl)]. Leber Magen Darm. 1976;6 (2):121-124

4. Urakami Y, Seifert E, Butke H. Peroral direct cholangioscopy (PDCS) using routine straight-view endoscope: first report. Endoscopy. 1977;9(1):27-30. doi:10.1055/s-0028-1098481

5. Nimura Y. [Percutaneous transhepatic cholangioscopy: technics and clinical studies]. Nihon Rinsho. 1984;42(10):2222-2227. Japanese.

6 . Chen YK. Preclinical characterization of the spyglass peroral cholangiopancreatoscopy system for direct access, visualization, and biopsy. Gastrointest Endosc. 2007;65(2):303-311. doi:10.1016/j. gie.2006.07.048

7. Lehibi AA, Aljahdali E, Balkhi AA, et al. The utility of digital cholangioscopy (SpyGlass DS) in biliary and pancreatic diseases: a clinical feasibility study at two tertiary care centers in Saudi Arabia (with Videos). Arab $J$ Gastroenterol. 2020;21(1):49-53. doi:10.1016/j.ajg.2019.12.003

8. Ayoub F, Yang D, Draganov PV. Cholangioscopy in the digital era. Transl Gastroenterol Hepatol. 2018;3:82. doi:10.21037/ $\operatorname{tgh} .2018 .10 .08$

9. Voaklander R, Kim E, Brown WH, Kasmin FE, Siegel JH. An overview of the evolution of direct cholangioscopy techniques for diagnosis and therapy. Gastroenterol Hepatol (N Y). 2016;12(7):433-437.

10. Tringali A, Lemmers A, Meves V, et al. Intraductal biliopancreatic imaging: European Society of Gastrointestinal Endoscopy (ESGE) technology review. Endoscopy. 2015;47(8):739-753. doi:10.1055/ s-0034-1392584

11. Ishida Y, Itoi T, Okabe Y. Types of peroral cholangioscopy: how to choose the most suitable type of cholangioscopy. Curr Treat Options Gastroenterol. 2016;14(2):210-219. doi:10.1007/s11938-016-0090-2

12. Franzini T, Moura RN, De moura EGH. Advances in therapeutic cholangioscopy. Gastroenterol Res Pract. 2016;2016:5249152. doi:10.1155/2016/5249152

13. Draganov PV, Lin T, Chauhan S, Wagh MS, Hou W, Forsmark CE. Prospective evaluation of the clinical utility of ERCP-guided cholangiopancreatoscopy with a new direct visualization system. Gastrointest Endosc. 2011;73(5):971-979. doi:10.1016/j. gie. 2011.01 .003

14. Shah RJ, Neuhaus H, Parsi M, Reddy DN, Pleskow DK. Randomized study of digital single-operator cholangioscope compared to fiberoptic single-operator cholangioscope in a novel cholangioscopy bench model. Endosc Int Open. 2018;6(7):E851-E856. doi:10.1055/a-05846458 
15. Pereira P, Peixoto A, Andrade P, Macedo G. Peroral cholangiopancreatoscopy with the SpyGlass ${ }^{\circledR}$ system: what do we know 10 years later. J Gastrointestin Liver Dis. 2017;26(2):165-170. doi:10.15403/ jgld.2014.1121.262.cho

16. Yasuda I, Itoi T. Recent advances in endoscopic management of difficult bile duct stones. Dig Endosc. 2013;25(4):376-385. doi: $10.1111 /$ den. 12118

17. Moon JH, Terheggen G, Choi HJ, Neuhaus H. Peroral cholangioscopy: diagnostic and therapeutic applications. Gastroenterology. 2013;144(2):276-282. doi:10.1053/j.gastro.2012.10.045

18. Beyna T, Farnik H, Sarrazin C, Gerges C, Neuhaus H, Albert JG. Direct retrograde cholangioscopy with a new prototype double-bending cholangioscope. Endoscopy. 2016;48(10):929-933. doi:10.1055/s-0042-110395

19. Sethi A, Shah RJ. Cholangioscopy and pancreatoscopy. Tech Gastrointest Endosc. 2017;19(3):182-187. doi:10.1016/j. tgie.2017.09.001

20. Ishida Y, Itoi T, Okabe Y. Current status and future perspective in cholangiopancreatoscopy. Curr Treat Options Gastroenterol. 2019;17 (3):327-341. doi:10.1007/s11938-019-00238-1

21. Tanisaka Y, Ryozawa S, Nonaka K, Ban S, Fujita A. Normal bile duct findings using peroral cholangioscopy-guided probe-based confocal laser endomicroscopy (with video). JGH Open. 2019;4(3):545-547. doi: $10.1002 /$ jgh3.12262

22. Franzini T, Moura RN, Bonifácio P, et al. Complex biliary stones management: cholangioscopy versus papillary large balloon dilation a randomized controlled trial. Endosc Int Open. 2018;6(2):E131E138. doi:10.1055/s-0043-122493

23. Mikhin AI, Orlov SY, Vasilenko KV, Sazhin AV. Endoscopic treatment of difficult common bile duct stones in elderly patients. Endoskopicheskaya Khirurgiya. 2019;25(1):53. doi:10.17116/ endoskop20192501153

24. Akase T, Yamamoto R, Abe T. A case of an incarcerated confluence stone removed completely by using spyglass DS-guided Electrohydraulic Lithotripsy (EHL). Pediatr Dermatol. 2019;95 (1):129-131.

25. Larghi A, Rimbaş M, Tringali A, Boškoski I, Rizzatti G, Costamagna G. Endoscopic radiofrequency biliary ablation treatment: a comprehensive review. Dig Endosc. 2019;31(3):245-255. doi:10.1111/den.13298

26. Singh A, Gelrud A, Agarwal B. Biliary strictures: diagnostic considerations and approach. Gastroenterol Rep. 2015;3(1):22-31. doi:10.1093/gastro/gou072

27. Burnett AS, Calvert TJ, Chokshi RJ. Sensitivity of endoscopic retrograde cholangiopancreatography standard cytology: 10-y review of the literature. J Surg Res. 2013;184(1):304-311. doi:10.1016/j. jss.2013.06.028

28. Miyazaki M, Yoshitomi H, Miyakawa S, et al. Clinical practice guidelines for the management of biliary tract cancers 2015: the 2nd English edition. $J$ Hepatobiliary Pancreat Sci. 2015;22 (4):249-273.

29. Miyabe K, Notohara K, Asano G, et al. Early detection of high-grade biliary intraepithelial neoplasia (BilIN-3) in the cystic duct visualized by SpyGlass DS cholangioscopy. Intern Med. 2021;60(1):47-52.

30. Mounzer R, Austin GL, Wani S, Brauer BC, Fukami N, Shah RJ. Per-oral video cholangiopancreatoscopy with narrow-band imaging for the evaluation of indeterminate pancreaticobiliary disease. Gastrointest Endosc. 2017;85(3):509-517. doi:10.1016/j.gie.2016.11.020

31. Osanai M, Itoi T, Igarashi $\mathrm{Y}$, et al. Peroral video cholangioscopy to evaluate indeterminate bile duct lesions and preoperative mucosal cancerous extension: a prospective multicenter study. Endoscopy. 2013;45(8):635-642.

32. Korrapati P, Ciolino J, Wani S, et al. The efficacy of peroral cholangioscopy for difficult bile duct stones and indeterminate strictures: a systematic review and meta-analysis. Endosc Int Open. 2016;4(3): E263-275. doi:10.1055/s-0042-100194
33. Navaneethan U, Hasan MK, Kommaraju K, et al. Digital, single-operator cholangiopancreatoscopy in the diagnosis and management of pancreatobiliary disorders: a multicenter clinical experience (with video). Gastrointest Endosc. 2016;84(4):649-655. doi:10.1016/j.gie.2016.03.789

34. Draganov PV, Chauhan S, Wagh MS, et al. Diagnostic accuracy of conventional and cholangioscopy-guided sampling of indeterminate biliary lesions at the time of ERCP: a prospective, long-term follow-up study. Gastrointest Endosc. 2012;75(2):347-353. doi:10.1016/j.gie.2011.09.020

35. Lenze F, Bokemeyer A, Gross D, Nowacki T, Bettenworth D, Ullerich H. Safety, diagnostic accuracy and therapeutic efficacy of digital single-operator cholangioscopy. United European Gastroenterol J. 2018;6(6):902-909. doi:10.1177/2050640618764943

36. Kanno Y, Koshita S, Ogawa T, et al. Peroral cholangioscopy by SpyGlass DS versus CHF-B260 for evaluation of the lateral spread of extrahepatic cholangiocarcinoma. Endosc Int Open. 2018;6(11): E1349-E1354. doi:10.1055/a-0743-5283

37. Kawakami H, Kuwatani M, Etoh K, et al. Endoscopic retrograde cholangiography versus peroral cholangioscopy to evaluate intraepithelial tumor spread in biliary cancer. Endoscopy. 2009;41(11):959-964.

38. Ogawa $\mathrm{T}$, Ito $\mathrm{K}$, Koshita $\mathrm{S}$, et al. Usefulness of cholangioscopic-guided mapping biopsy using SpyGlass DS for preoperative evaluation of extrahepatic cholangiocarcinoma: a pilot study. Endosc Int Open. 2018;6(2):E199-E204.

39. Lee YN, Moon JH, Choi HJ, et al. Direct peroral cholangioscopy using an ultraslim upper endoscope for management of residual stones after mechanical lithotripsy for retained common bile duct stones. Endoscopy. 2012;44(9):819-824. doi:10.1055/s-0032-1309880

40. Kim CW, Chang JH, Lim YS, Kim TH, Lee IS, Han SW. Common bile duct stones on multidetector computed tomography: attenuation patterns and detectability. World $J$ Gastroenterol. 2013;19 (11):1788-1796. doi:10.3748/wjg.v19.i11.1788

41. Adler DG, Facg A. Endoscopic ultrasound after ercp to assess for residual stones. NEJM J Watch. 2019. Available from: https://www. jwatch.org/na49981/2019/09/27/endoscopic-ultrasound-after-ercpassess-residual-stones.

42. Alaubaidi TI, Ghadhban BR, Chitheer SS. Does preoperative magnetic resonant cholangiopancreatography (MRCP), improve the safety of laparoscopic cholecystectomy? Int $J$ Surg Open. 2018;15:7-13. doi:10.1016/j.ijso.2018.09.002

43. Huang SW, Lin CH, Lee MS, Tsou YK, Sung KF. Residual common bile duct stones on direct peroral cholangioscopy using ultraslim endoscope. World J Gastroenterol. 2013;19(30):4966-4972. doi:10.3748/wjg.v19.i30.4966

44. Yang JJ, Liu XC, Chen XQ, Zhang QY, Liu TR. Clinical value of DPOC for detecting and removing residual common bile duct stones (video). BMC Gastroenterol. 2019;19(1):135. doi:10.1186/s12876019-1045-6

45. Rizvi S, Gores GJ. Pathogenesis, Diagnosis, and Management of Cholangiocarcinoma. Gastroenterology. 2013;145(6):1215-1229. doi:10.1053/j.gastro.2013.10.013

46. Chang JH, Lee I, Choi MG, Han SW. Current diagnosis and treatment of benign biliary strictures after living donor liver transplantation. World J Gastroenterol. 2016;22(4):1593-1606. doi:10.3748/wjg.v22.i4.1593

47. Mchenry L, Lehman GA. Difficult bile duct stones. Curr Treat Options Gastroenterol. 2006;9(2):123-132. doi:10.1007/s11938006-0031-6

48. Arya N, Nelles SE, Haber GB, Kim YI, Kortan PK. Electrohydraulic lithotripsy in 111 patients: a safe and effective therapy for difficult bile duct stones. Am J Gastroenterol. 2004;99(12):2330-2334. doi:10.1111/j.1572-0241.2004.40251.x

49. Robles-Medranda C, Soria-Alcívar M, Oleas R, et al. Digital per-oral cholangioscopy to diagnose and manage biliary duct disorders: a single-center retrospective study. Endosc Int Open. 2020;8(6):E796E804. doi:10.1055/a-1153-8950 
50. Brewer GOI, Bekkali NLH, Raijman I, et al. Efficacy and safety of digital single-operator cholangioscopy for difficult biliary stones. Clin Gastroenterol Hepatol. 2018;16(6):918-926.e1. doi:10.1016/j. cgh.2017.10.017

51. Moon JH, Ko BM, Choi HJ, et al. Direct peroral cholangioscopy using an ultra-slim upper endoscope for the treatment of retained bile duct stones. Am J Gastroenterol. 2009;104(11):2233-2729. doi:10.1038/ajg.2009.435

52. Barakat MT, Girotra M, Choudhary A, Huang RJ, Sethi S, Banerjee S. A prospective evaluation of radiation-free direct solitary cholangioscopy for the management of choledocholithiasis. Gastrointest Endosc. 2018;87 (2):584-589.e1. doi:10.1016/j.gie.2017.07.042

53. Buxbaum J, Sahakian A, Ko C, et al. Randomized trial of cholangioscopy-guided laser lithotripsy versus conventional therapy for large bile duct stones (with videos). Gastrointest Endosc. 2018;87 (4):1050-1060. doi:10.1016/j.gie.2017.08.021

54. Strand DS, Cosgrove ND, Patrie JT, et al. ERCP-directed radiofrequency ablation and photodynamic therapy are associated with comparable survival in the treatment of unresectable cholangiocarcinoma. Gastrointest Endosc. 2014;80(5):794-804. doi:10.1016/j.gie.2014.02.1030

55. Dolak W, Schreiber F, Schwaighofer H, et al.; Austrian Biliary RFA Study Group. Endoscopic radiofrequency ablation for malignant biliary obstruction: a nationwide retrospective study of 84 consecutive applications. Surg Endosc. 2014;28(3):854-860. doi:10.1007/s00464013-3232-9

56. Mensah ET, Martin JR, Topazian M. Radiofrequency ablation for biliary malignancies. Curr Opin Gastroenterol. 2016;32(3):238-243.

57. Ogura T, Onda S, Sano T, et al. Evaluation of the safety of endoscopic radiofrequency ablation for malignant biliary stricture using a digital peroral cholangioscope (with videos). Dig Endosc. 2017;29 (6):712-717. doi:10.1111/den.12837
58. Lee YY, Gwak GY, Lee KH, et al. Predictors of the feasibility of primary endoscopic management of biliary strictures after adult living donor liver transplantation. Liver Transpl. 2011;17 (12):1467-1473. doi:10.1002/lt.22432

59. Bokemeyer A, Gross D, Brückner M, et al. Digital single-operator cholangioscopy: a useful tool for selective guidewire placements across complex biliary strictures. Surg Endosc. 2019;33(3):731-737. doi:10.1007/s00464-018-6334-6

60. Tyberg A, Zerbo S, Kahaleh M, Sharaiha RZ. Digital cholangioscopy-assisted gallbladder drainage: seeing is accessing. Endoscopy. 2015;47 (Suppl 1):E417.

61. Sejpal DV, Vamadevan AS, Trindade AJ. Removal of an embedded, migrated plastic biliary stent with the use of cholangioscopy. Gastrointest Endosc. 2015;81(6):1482-1483. doi:10.1016/j. gie.2014.12.015

62. Turowski F, Hügle U, Dormann A, et al. Diagnostic and therapeutic single-operator cholangiopancreatoscopy with SpyGlassDSTM: results of a multicenter retrospective cohort study. Surg Endosc. 2018;32 (9):3981-3988. doi:10.1007/s00464-018-6141-0

63. Sethi A, Chen YK, Austin GL, et al. ERCP with cholangiopancreatoscopy may be associated with higher rates of complications than ERCP alone: a single-center experience. Gastrointest Endosc. 2011;73(2):251-256. doi:10.1016/j.gie.2010.08.058

64. Mukewar S, Gorospe EC, Knipschield MA, Bingener J, Gostout C. Effects of carbon dioxide insufflation during direct cholangioscopy on biliary pressures and vital parameters: a pilot study in porcine models. Gastrointest Endosc. 2017;85(1):238-242.e1. doi:10.1016/j. gie. 2016.06 .020
International Journal of General Medicine

\section{Publish your work in this journal}

The International Journal of General Medicine is an international, peer-reviewed open-access journal that focuses on general and internal medicine, pathogenesis, epidemiology, diagnosis, monitoring and treatment protocols. The journal is characterized by the rapid reporting of reviews, original research and clinical studies

\section{Dovepress}

across all disease areas. The manuscript management system is completely online and includes a very quick and fair peer-review system, which is all easy to use. Visit http://www.dovepress.com/ testimonials.php to read real quotes from published authors. 